\title{
PENINGKATAN USAHA PENGRAJIN TEDUNG LUKIS MELALUI PENERAPAN IPTEK
}

\section{INCREASED BUSINESS CRAFTMEN TEDUNG LUKIS THROUGH THE IMPLEMENTATION OF SCIENCE}

\author{
Riza Wulandari ${ }^{1)}$, I Wayan Gede Lamopia ${ }^{2) *}$, Ni Nyoman Wulan Antari ${ }^{3)}$ \\ ${ }^{1)}$ Fakultas Informatika dan Komputer, Institut Teknologi dan Bisnis Stikom Bali \\ email: rizawulandari@stikom-bali.ac.id \\ ${ }^{2)}$ Fakultas Informatika dan Komputer, Institut Teknologi dan Bisnis Stikom Bali \\ email: wayanlamo@gmail.com \\ ${ }^{3)}$ Fakultas Informatika dan Komputer, Institut Teknologi dan Bisnis Stikom Bali
}

\begin{abstract}
ABSTRAK
Tedung Lukis adalah salah satu warisan budaya yang dimiliki oleh masyarakat Bali. Sesuai perkembangan jaman, Tedung Lukis mulai banyak diminati oleh masyarakat, selain untuk upacara keagamaan umat Hindu, tedung lukis bisa digunakan sebagai aksen interior maupun eksterior untuk rumah, hotel, maupun restoran. Sasaran konsumen tidak hanya berasal dari domestic namun juga mancanegara. Usaha beliau sudah berjalan kurang lebih 5 tahun dengan dibantu oleh 4 karyawan. Mitra ini mengalami permasalahan pada produksi yakni kekurangan alat dan branding identitas dimana tidak memiliki brand logo serta kurangnya pemasaran. Penyelesaian permasalahan yang terjadi pada UKM Tedung Lukis Bali adalah pemberian desain logo dan pembuatan Instagram sebagai media pemasaran Payung Tedung Lukis Bali. Selain itu, untuk menunjang efektivitas dan efisiensi waktu produksi Tedung Lukis, mitra diberikan alat pendukung berupa mesin serut. Menurut mitra, kegiatan ini sangat memberikan manfaat bagi usaha Tedung Lukis Bali.
\end{abstract}

Kata kunci: Peningkatan Usaha, IPTEK, UKM Tedung Lukis Bali

\section{ABSTRACT}

Tedung Lukis is one of the cultural heritage owned by the Balinese people. According to the development era. Tedung Lukis serpents began to be in demand by the community, other than for Hindu religious ceremonies, painting fiery serpents can be used as an interior or exterior accent for the house, hotel, and restaurant. Target consumers not only come from domestic but also foreign. His efforts have been about 5 years with assisted by 4 employees. These partners are experiencing problems in the production of tool shortage and identity branding where there is no brand logo and lack of marketing. Solving problems that occur in Tedung Lukis is to give the logo design and creation of Instagram as a marketing medium of Bali Tedung Lukis. In addition, to support the effectiveness and efficiency of production of Tedung Lukis, partners are given supporting tools in the form of a drawstring machine. According to partners, this activity is very beneficial for the efforts of the Tedung Lukis Bali.

Keywords: Business enhancement, IPTEK, Tedung Lukis Bali

\section{PENDAHULUAN}

Warisan budaya merupakan sebuah istilah yang telah mengalami perubahan arti, berakhir pada monumen dan koleksi bendabudaya mengalami pergeseran arti yang jauh benda, warisan budaya juga termasuk dalam berbeda dalam beberapa dekade terakhir. tradisi atau ekspresi hidup yang diwarisi dari Sebagian besar perubahan tersebut karena nenek moyang dan diteruskan kepada 
keturunannya, seperti tradisi lisan, seni pendapatan perkapita maupun meningkatkan pertunjukan, praktik sosial, ritual, acara perekonomian suatu daerah. [1] Pelaku meriah, pengetahuan dan praktek tentang UKM dituntut mampu untuk ikut serta dalam alam dan alam semesta atau pengetahuan mengembangkan perekonomian negaranya dan keterampilan untuk menghasilkan terutama dalam melakukan pengembangan kerajinan tradisional. Pelestarian pusaka hal apapun guna memenuhi permintaan budaya membantu masyarakat tidak hanya konsumen yang semakin spesifik, inovatif, melindungi aset fisik bernilai ekonomis, memiliki harga yang terjangkau namun tetap tetapi juga melestarikan praktik, sejarah, dan berkualitas sampai dengan dapat bersaing lingkungan, dan rasa kontinuitas dan secara global mengingat mulai memasuki identitas. Dalam melestarikan warisan yang masyarakat ekonomi ASEAN. Data bisa berdampak pada pembangunan ekonomi perkembangan koperasi dan UKM di diperlukan aktor pelaku ekonomi seperti Provinsi Bali dapat dilihat pada gambar di wirausaha yang menunjang pertumbuhan bawah ini. tersebut [2].

Pertumbuhan ekonomi sebagai sebuah proses peningkatan output dari waktu ke waktu menjadi indikator penting untuk mengukur keberhasilan pembangunan suatu negara. Keberhasilan suatu negara dalam meningkatkan kesejahteraan masyarakatnya diukur melalui tingkat pertumbuhan ekonomi yang berhasil dicapai. Pertumbuhan ekonomi yang tinggi dan stabil dari tahun ke tahun berarti kesejahteraan ekonomi meningkat, sedangkan pertumbuhan ekonomi dengan nilai negatif berarti tingkat kesejahteraan disuatu negara juga menurun. Tinggi rendah laju pertumbuhan ekonomi di suatu negara menunjukkan tingkat perubahan kesejahteraaan ekonomi masyarakatnya [3]. Di Indonesia khususnya di Bali, UKM juga sangat berperan sebagai roda penggerak pembangunan ekonomi. Selain itu, peran pelaku UKM dipandang sangat penting guna meningkatkan

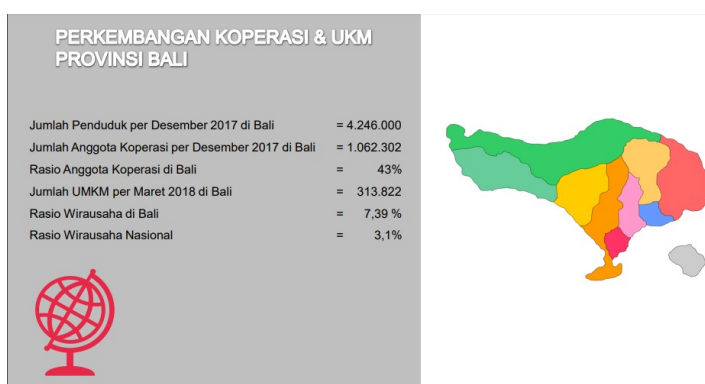

Gambar. 1 Perkembangan Koperasi dan UKM Provinsi Bali [4]

UKM Tedung Lukis merupakan pengrajin payung yang biasa digunakan dalam upacara keagamaan di Pura. Menurut Ida Pedanda Wayan tedung saat ini tidak hanya digunakan dalam upacara keagamaan, tetapi sebagai hiasan interior dan eksterior sebuah rumah atau kantor serta bisa digunakan sebagai simbol pariwisata. UKM Tedung Lukis ini memiliki ciri khas yang berbeda dengan para pengrajin tedung lainnya. Hal ini terlihat pada pembuatan tedung yang memanfaatkan seni lukis sehingga membuat tedung menjadi lebih menarik. Bapak Wayan Eka Purnama adalah salah satu pengrajin yang memproduksi 
tedung lukis Bali. UKM Tedung Lukis milik menggunakan alat manual. Begitu pula beliau ini terletak di Banjar Abasan, terjadi pada proses pembuatan tiang kayu, Singapadu Tengah, Sukawati Gianyar. tiang kayu yang digunakan sebagai Melihat desain dari tedung Bali yang masih penyangga payung harus diserut dan di monoton, beliau mencoba membuat sebuah amplas dengan menggunakan pisau. Pada kreasi baru dengan menghadirkan seni lukis pembuatan Tedung Lukis dengan agar Tedung Bali lebih menarik untuk menggunakan alat manual ini, mitra hanya dipasarkan ke wisatawan domestik maupun bisa memproduksi 3-5 tedung lukis dalam mancanegara. Usaha Tedung Lukis dirintis waktu 1 minggu. Hal tersebut cukup menyita pada tahun 2014 dengan dibantu oleh 1 waktu pada pengerjaan serut bambu dan karyawan dan seiring berkembangnya usaha amplas kayu. Bambu sebagai bahan baku beliau kini sudah memiliki 4 karyawan. dari jari-jari payung harus diserut secara Ringkasan analisis situasi UKM Tedung halus dan memiliki ukuran yang sepadan Lukis milik Bapak Wayan Eka Purnama antara bambu satu dengan yang lain. Setelah yang terjadi saat ini dapat dilihat pada tabel mengerjakan serutan bambu, mitra masih dibawah ini Usaha Tedung Lukis ini tidak harus melakukan penghalusan pada jari jari selalu berjalan mulus. Hambatan dan dan juga tiang kayu yang digunakan sebagai permasalahan yang dialami oleh mitra adalah penyangga. Berikut situasi kondisi saat ini dari segi produksi dan pemasaran. Pada segi yang dialami mitra dengan melihat dari produksi, pembuatan jari-jari payung masih kuantitas produksi dan pemasaran.

Tabel 1 Situasi Kondisi Produksi Mitra Saat ini dalam Angka

\begin{tabular}{|l|l|l|l|}
\hline No. & \multicolumn{1}{|c|}{ Uraian } & \multicolumn{1}{|c|}{\begin{tabular}{c}
\multicolumn{1}{|c|}{ Waktu } \\
(hari/minggu/bulan)
\end{tabular}} & \multicolumn{1}{c|}{ Qty } \\
\hline 1. & Produksi Jari - Jari Payung & 1 minggu & 3-5 kerangka jari payung \\
\hline 2. & Strategi Pemasaran & 1 minggu & 0 \\
\hline 3 & $\begin{array}{l}\text { Produksi Pembuatan Tiang } \\
\text { Kayu }\end{array}$ & 1 minggu & $5-7$ tiang penyangga \\
\hline
\end{tabular}

Proses pembuatan jari-jari payung dan tiang secara manual bisa dilihat pada gambar disamping ini.

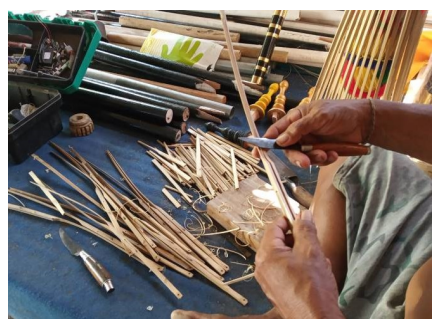

Gambar. 2 Permasalahan pada Proses Serut Secara Manual

Melihat analisis situasi diatas, maka perlu diberikan solusi untuk memecahkan permasalahan yang dialami mitra yaitu pada proses produksi yang masih manual dan tidak efisien serta branding identitas. Tujuan dari tim pelaksana kegiatan pengabdian masyarakat ini adalah membantu UKM dalam meningkatkan usaha melalui pemenuhan alat pada proses produksi untuk mendapatkan kualitas terbaik sehingga pelanggan akan lebih puas dalam melakukan pemesanan Tedung Lukis Bali. Selain itu, menumbuhkan eksistensi usaha dengan cara 
yang lebih modern yaitu memanfaatkan alat mesin serut dan mesin amplas serta

digital berupa media sosial

METODE PELAKSANAAN KEGIATAN

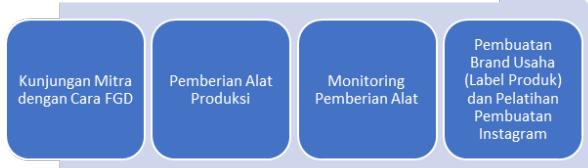

Gambar. 3 Rencana Kegiatan

Berdasarkan permasalahan prioritas yang terjadi pada kondisi mitra kegiatan pengabdian masyarakat, maka akan dilakukan tahapan rencana kegiatan yang akan dilakukan diantaranya sebagai berikut :

\section{Kunjungan Mitra}

Pada tahap rencana kunjungan mitra, hal hal yang akan dilakukan pada kunjungan tersebut adalah mengadakan focus group discussion untuk mendiskusikan program kemitraan masyarakat di UKM Tedung Lukis Bali dan menemukan starting point permasalahan mitra.

2. Pemberian alat produksi

Pemberian alat produksi diberikan kepada mitra UKM Tedung Lukis Bali berupa mesin serut dan mesin amplas. Harapan dari pemberian alat produksi ini adalah mempermudah dan mempercepat proses pembuatan yang awalnya masih bersifat manual kini sudah beralih dengan memanfaatkan teknologi tepat guna. Kegiatan pengabdian masyarakat ini juga memberikan pelatihan terkait penggunaan pemeliharaan dari alat tersebut. Pada proses pembelian alat produksi, tim pengusul mengajak penjual mesin untuk mempraktekkan cara penggunaan mesin serut dan amplas. Sosialisasi tentang pelatihan dan perawatan mesin ini perlu diberikan mengingat mitra sebelumnya hanya menggunakan alat manual untuk memproduksi tedung lukis Bali ini.

\section{Monitoring}

Monitoring bertujuan untuk melihat aktifitas dari mitra UKM Tedung Lukis Bali setelah diberikan alat produksi. Kebermanfaatan alat produksi yang diberikan sangat berpengaruh bagi keberhasilan dari program kemitraan masyarakat ini. Pada proses monitoring juga dihadirkan narasumber yakni pengrajin pembuatan kayu bambu sebagai rangka untuk memberikan pelatihan pengolahan kayu bambu.

4. Pembuatan Label Produk dan Pelatihan pembuatan Media Online Instagram

Pembuatan label produk akan dikerjakan oleh tim pendukung dari kegiatan pengabdian masyarakat. Label ini dibuat berdasarkan keinginan mitra mulai dari warna dan desain yang diinginkan. Setelah membuat label produk, mitra akan dibuatkan media online Instagram dan diberikan pelatihan dalam penggunaan media sosial yang bisa menjadi sarana bagi mitra dan pembeli dengan cara yang lebih mudah. 
Kegiatan pengabdian masyarakat ini dilaksanakan di Desa Singapadu Tengah, tidak terlepas konseptual kajian ilmiah Kecamatan Gianyar. Sasaran utama dalam pengusul tentang pentingnya pelaksanaan kegiatan pengabdian mempertahankan identitas kultural yang masyarakat sebagai wujud transfer berjudul Konstruksi Identitas Kultural Desa knowledge adalah Bapak Wayan Eka Panglipuran. Penelitian ini mengungkapkan Purnama yang memiliki usaha dalam bidang bahwa di era globalisasi saat ini, masyarakat kerajinan tangan Payung Tedung Lukis. perlu memiliki spirit dalam hal warisan Adapun jadwal kegiatan pelaksanaan budaya yang menjadi identitas Pulau Bali [5] pengabdian masyarakat di Desa Singapadu Tengah pada sasaran mitra pengrajin Payung

HASIL DAN PEMBAHASAN Tedung Lukis Bali adalah sebagai berikut :

\section{Timeline Kegiatan}

Pengabdian masyarakat yang diusung oleh pelaksana ITB STIKOM Bali kali ini

Tabel 1 Timeline Kegiatan 1

\begin{tabular}{|c|c|c|}
\hline Target Sasaran Kegiatan & Uraian Kegiatan & Tgl \\
\hline $\begin{array}{l}\text { Pengrajin Tedung Lukis } \\
\text { (Bp. Wayan Eka } \\
\text { Purnama) }\end{array}$ & $\begin{array}{l}\text { Kunjungan Mitra (informal). Jarak usaha mitra } \\
\text { dengan ketua tim pelaksana tergolong cukup } \\
\text { dekat, sehingga tidak memerlukan waktu yang } \\
\text { cukup lama untuk mendiskusikan rencana } \\
\text { kegiatan pengabdian masyarakat yang akan } \\
\text { dijalankan. }\end{array}$ & $10 / 01 / 20$ \\
\hline $\begin{array}{l}\text { Tim Pelaksana dan } \\
\text { Pengrajin Tedung Lukis }\end{array}$ & $\begin{array}{l}\text { Setelah menemukan starting point pada tanggal } 10 \\
\text { Januari 2020. Tim pelaksana kemudian } \\
\text { melaksanakan agenda rapat untuk membahas } \\
\text { persiapan pembuatan desain logo serta strategi } \\
\text { pemasaran yang akan diberikan kepada mitra } \\
\text { yakni Instagram bisnis. }\end{array}$ & $11 / 01 / 20$ \\
\hline $\begin{array}{l}\text { Pengrajin Tedung Lukis } \\
\text { (Bp. Wayan Eka } \\
\text { Purnama) dan karyawan }\end{array}$ & $\begin{array}{l}\text { Penyerahan Desain Logo dan Instagram Bisnis } \\
\text { kepada mitra Bp. Wayan Eka Purnama. }\end{array}$ & $18 / 01 / 20$ \\
\hline $\begin{array}{l}\text { Pengrajin Tedung Lukis } \\
\text { (Bp. Wayan Eka } \\
\text { Purnama) dan karyawan }\end{array}$ & $\begin{array}{l}\text { Rapat koordinasi evaluasi kegiatan pengabdian } \\
\text { masyarakat tahap I }\end{array}$ & $18 / 01 / 20$ \\
\hline $\begin{array}{l}\text { Pengrajin Tedung Lukis } \\
\text { (Bp. Wayan Eka } \\
\text { Purnama) dan karyawan }\end{array}$ & $\begin{array}{l}\text { - Pemberian alat serut B882 untuk memudahkan } \\
\text { mitra dalam menghaluskan kayu. Alat ini } \\
\text { sangat bermanfaat secara efisien dan kualitas } \\
\text { - Pemberian Desain Logo Payung Tedung Lukis } \\
\text { Bali }\end{array}$ & \multirow[t]{2}{*}{$\begin{array}{l}18 \text { April } \\
2020\end{array}$} \\
\hline $\begin{array}{l}\text { Pengrajin Tedung Lukis } \\
\text { (Bp. Wayan Eka } \\
\text { Purnama) dan karyawan }\end{array}$ & Evaluasi II kegiatan pengabdian masyarakat & \\
\hline
\end{tabular}

\section{Pelaksanaan Kegiatan}

a. Pemberian Desan Logo dan Pemasaran 


\section{Instagram}

Pelaksanaan kegiatan pengabdian masyarakat pada usaha Payung Tedung Lukis di Singapadu Tengah, Gianyar dilakukan dengan beberapa tahap. Pada tahapan pertama, kegiatan yang diberikan adalah pemberian desain logo dan Instagram bisnis sesuai dengan permasalahan yang dihadapi oleh Pengrajin Payung Tedung Lukis Bapak Wayan Eka Purnama. Pembuatan Desain Logo Payung Tedung Lukis dibuat dengan menggunakan aplikasi Adobe Photoshop CS6. Aplikasi ini dirasakan cukup mempermudah dalam pembuatan desain. Terdapat dua draft desain yang telah dibuat dengan tidak meninggalkan karakter identitas dari Kerajinan Payung Tedung Lukis Bali. Pada Desain 1 (Gambar 4.1) pembuatan desain tersebut mencerminkan usaha yang digeluti oleh Bp. Wayan Eka Purnama yakni Payung. Namun Desain pada saat didiskusikan oleh Bp. Wayan Eka Purnama di kunjungan 3 tanggal 18 Januari 2020, beliau masih kurang berkenan dengan desain ini. Sehingga ketua tim pelaksana memberikan pilihan desain lain.

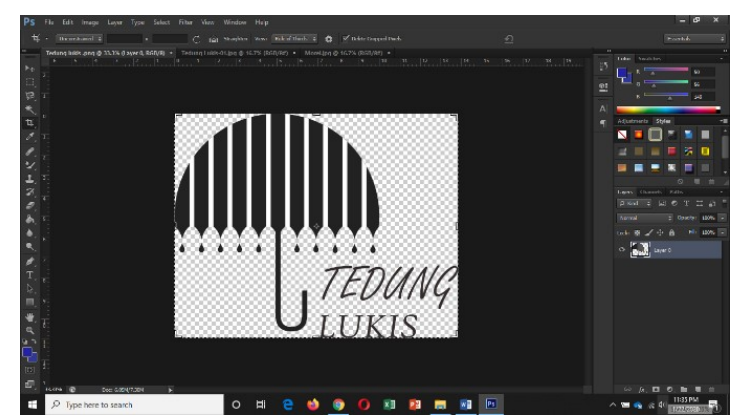

Gambar. 4 Desain Pertama Payung Tedung Lukis
Pada desain kedua, masih dengan menggunakan adobe photoshop CS6. Desain ini terlihat lebih memunculkan karakter yakni adanya kuas lukis dan desain payung di pinggir gambar, sehingga gambar 5 yang dipilih oleh mitra untuk dijadikan sebagai logo dari Payung Tedung Lukis Bali.

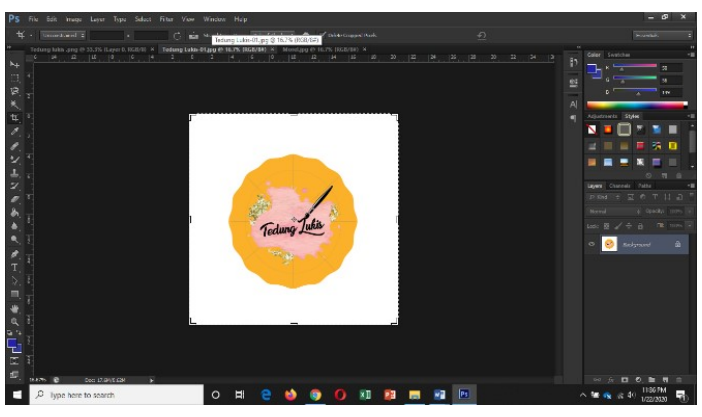

Gambar. 5 Desain Kedua Payung Tedung Lukis

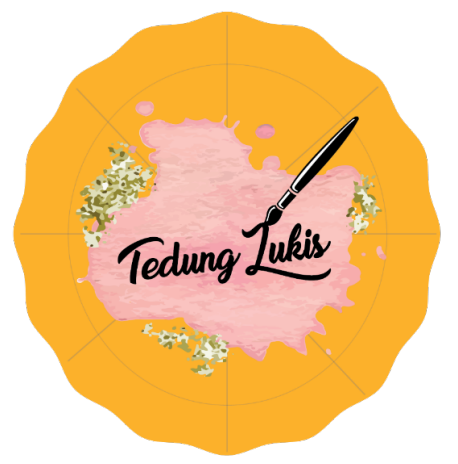

Gambar. 6 Hasil Akhir Logo Usaha Payung Tedung Lukis

Gambar di atas merupakan hasil akhir dari pembuatan desain logo dengan menggunakan Adobe Photoshop CS6 yang dipilih oleh mitra. Pembahasan kegiatan selanjutnya adalah pembuatan Instagram bisnis dari usaha Payung Tedung Lukis. 


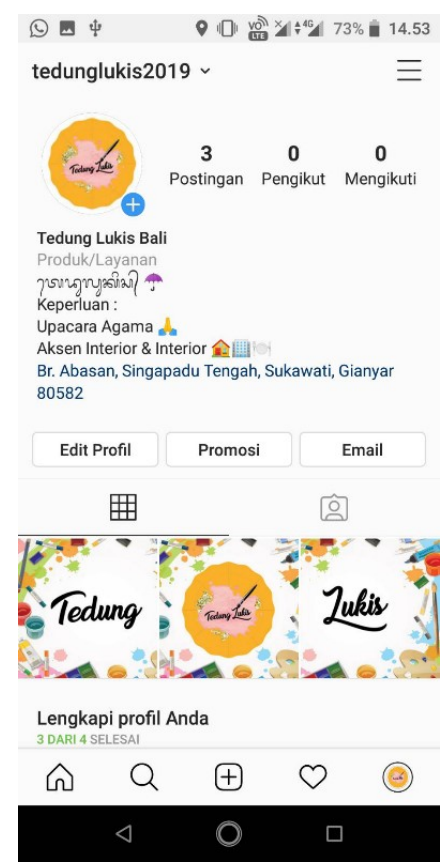

Gambar. 7 Hasil Pembuatan Instagram Tedung Lukis Bali

b.Pemberian Alat Penunjang untuk Mitra

Sebagai salah satu wujud peningkatan usaha UKM Tedung Lukis Bali, tim pengabdian masyarakat juga mendukung rencana tersebut dengan memberikan alat penunjang berupa Mesin Serut. Mesin serut ini sangat bermanfaat bagi mitra dalam menghaluskan kayu yang biasanya menggunakan pisau secara manual. Kini dengan alat yang canggih berupa Mesin Serut, mereka bisa lebih memaksimalkan pembuatan Tedung Lukis. Berikut adalah dokumentasi penyerahan alat oleh Tim Pengabdian Masyarakat.
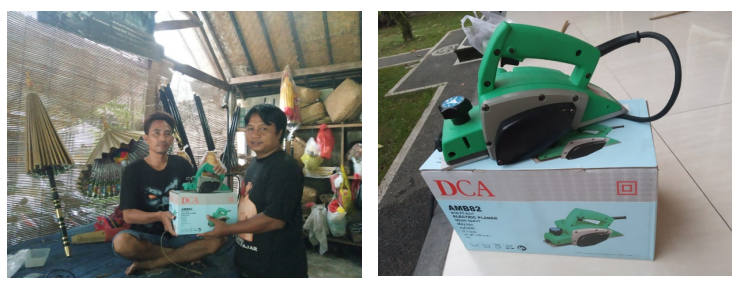

Gambar. 8 Penyerahan Alat Penunjang Mesin Serut untuk Mitra
Penyerahan ini dilakukan oleh ketua pelaksana Bapak I Wayan Gede Lamopia dan diserahkan kepada Bapak Wayan Eka Purnama. Dalam proses penyerahan alat ini sangat sederhana hanya dihadiri oleh Ketua Pelaksana. Pembatasan kegiatan masyarakat akibat Pandemi Covid19 mengharuskan hanya satu orang dari team pengabdian yang berangkat. Selain dihadiri oleh Bapak Wayan Gede Lamopia, pelaksanaan kegiatan dengan memberikan alat penunjang ini juga dihadiri oleh pengrajin senior yang sudah menggunakan alat serut dalam membuat payung tedung. Beliau diminta hadir untuk memberikan pelatihan penggunaan alat serut untuk kayu yang nantinya untuk jari-jari payung. Dokumentasi pelatihan dapat dilihat pada gambar ini.

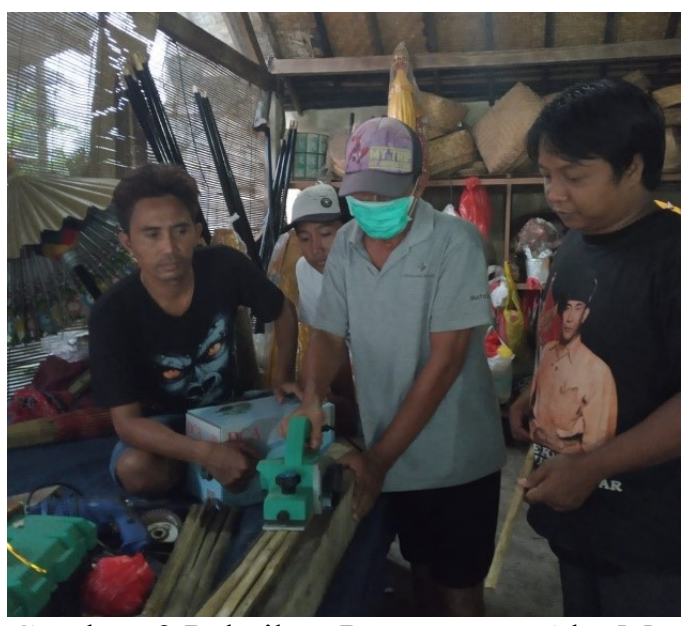

Gambar. 9 Pelatihan Penggunaan Alat Mesin Serut oleh Bapak Pande Suastika

Hasil dari kayu yang diserut dengan menggunakan pisau dan mesin dapat dilihat pada gambar dibawah ini 


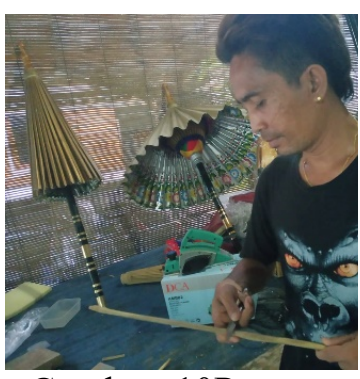

Gambar. 10Proses serut Manual

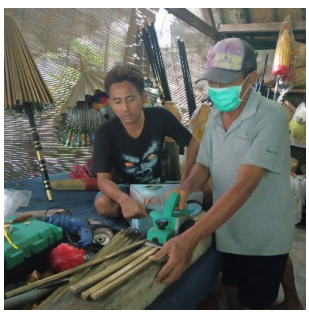

Gambar. 12

Proses Serut

Kayu Bambu

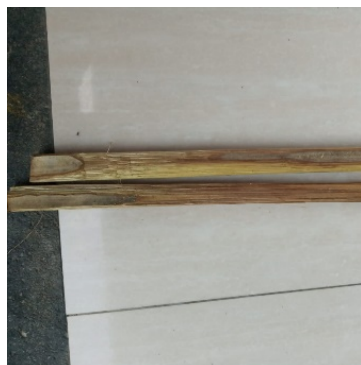

Gambar. 11 Hasil Serut Manual

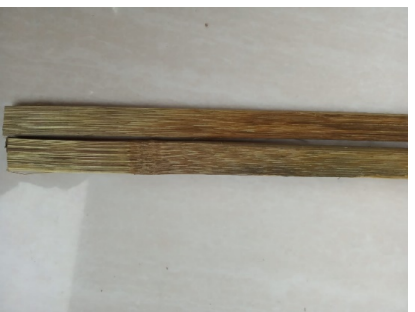

Gambar. 13 Hasil Serut Menggunakan Mesin lebih Halus

\section{Monitoring Kegiatan}

Proses pembuatan desain logo dan Instagram bisnis untuk usaha Payung Tedung Lukis bali telah dijelaskan diatas. Kegiatan pengabdian masyarakat tidak berhenti sampai pada pemberian akun media sosial dan desain logo. Tim Pelaksana khususnya pada ketua kemudian memberikan pelatihan sederhana terkait penggunaan Instagram bisnis kepada mitra. Kegiatan ini dapat dilihat pada gambar di bawah ini.
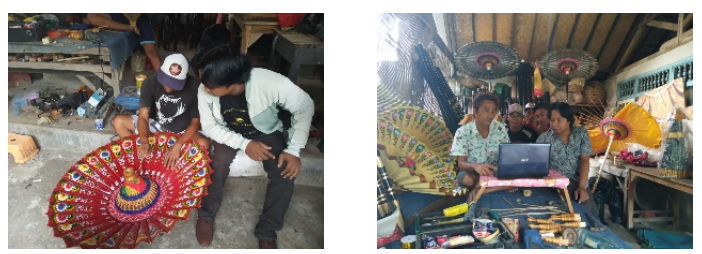

Gambar. 14 Kegiatan Monitoring Pengabdian Masyarakat

Setelah melakukan monitoring, tim

pelaksana kemudian melakukan penentuan luaran dari kegaitan pengabdian masyarakat. Hasil luaran kegiatan pengabdian masyarakat ini dapat dilihat pada gambar dibawah ini.

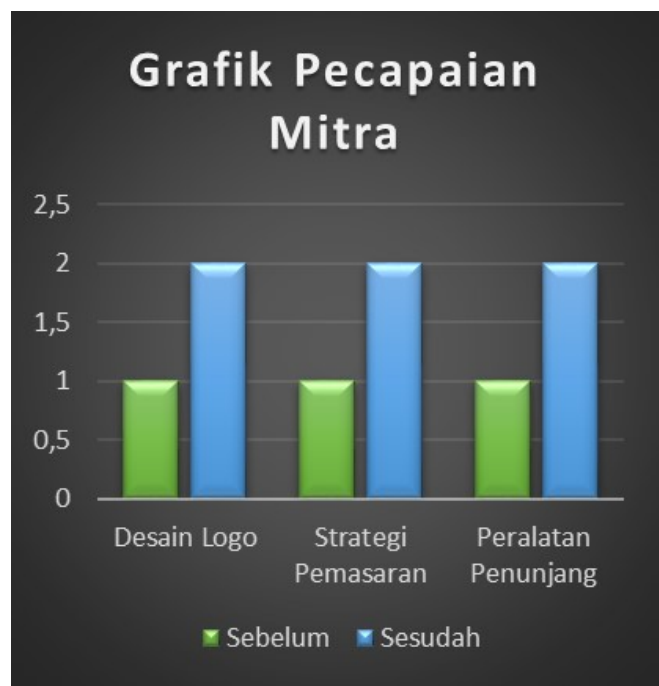

Gambar. 15 Grafik Capaian Mitra (Luaran Pengabdian Masyarakat)

\section{KESIMPULAN}

Payung Tedung Lukis Bali adalah salah satu atribut yang sering digunakan dalam proses upacara. Kemajuan pola pikir membuat payung tedung lukis ini berkembang fungsinya yaitu digunakan sebagai hiasan dalam hotel, restaurant maupun desain-desain interior indoor maupun outdoor. Kegiatan pengabdian masyarakat dalam rangka meningkatkan usaha payung tedung lukis melalui penerapan IPTEK telah dilaksanakan dengan baik. Tim pelaksana pengabdian telah membantu untuk menyelesaikan permasalahan yang dihadapi oleh mitra. Kini, mitra sudah memiliki media pemasaran berupa brand logo dan Instagram yang 
diharapkan bisa meningkatkan usaha mitra. adalah I Made Dwika Putra dan I Dewa Selain itu, kualitas hasil produksi mitra kini Made Septana Yosa.

jauh lebih baik dari sebelumnya dimana mitra masih melakukan serut kayu dengan cara manual kini sudah lebih efektif dan efisien dengan menggunakan Mesin Serut.

\section{SARAN}

Pelaksanaan kegiatan pengabdian masyarakat cukup berjalan dengan lancar. Adapun saran yang bisa membangun usaha setelah pelaksanaan kegiatan ini adalah mitra sebaiknya terus mengasah kemampuan untuk menggunakan media sosial yang telah dibuat agar bisa digunakan secara efisien dan terus menerus

\section{UCAPAN TERIMAKASIH}

Kegiatan pengabdian masyarakat ini tidak terlepas dari pihak-pihak terkait yang telah membantu tim pelaksana diantaranya

\section{REFERENSI}

[1] Boediono. (2013). Seri Sinopsis Pengantar Ilmu Ekonomi No.1 Ekonomi Mikro. BPFE.

[2] D. P. d. K. R. (1998). Sejarah Kebudayaan Bali: Kajian Perkembangan Dan Dampak Pariwisata. CV. Eka Dharma.

[3] Ni Nyoman Wulan Antari, R. W. (2019). Penguatan Identitas Melalui Branding Kemasan dan Diversifikasi Produk Usaha Comel. Jurnal Studi Kasus Inovasi Ekonomi, 3(1).

[4] Disperindag Bali, 2017

[5] Lamopia, I. W. G. (2019). Tourism Based Cultural Identity Construction In Penglipuran Village of Bangli. Proceedings the 5th International Conferences on Cultural Studies, Udayana University Towards the Development of Trans-Disciplinary Research Collaboration in the Era of Global Disruption. 